\title{
ON THE GENERALIZED CONCEPT OF ENTROPY FOR PHYSICAL, EXTRA- PHYSICAL AND CHEMICAL PROCESSES
}

\author{
Giovanni Nicoletti *, Natale Arcuri, Roberto Bruno and Gerardo Nicoletti \\ ${ }^{a}$ Department of Mechanical, Energetic and Management Engineering (DIMEG) -University of Calabria \\ Zip 87030 - ARCAVACATA DI RENDE (CS) - Italy
}

Email: giovanni.nicoletti@unical.it

\begin{abstract}
The article presents some examples of entropy production in physical, extra-physical and chemical processes in order to demonstrate the possibility of generalizing this surprising parameter. In physical processes, the entropy assumes great significance for introduction to the second law of thermodynamics, and it is defined by means of a simple formulation of a Pfaff differential. Instead, in chemical processes, the entropic evaluations are described by the Gibbs thermodynamic theory. Concerning entropic analysis, the considered physical and chemical processes regard two different practical cases in thermodynamic science: the transfer of thermal energy in heat exchangers and combustion reactions. In particular, by means of entropic production, a comparison between different types of heat exchangers and the ecological goodness of some fuels in heat production, have been investigated. By using the information theory of Shannon and Weaver, the entropy notion extends its applicability domain, exploiting this concept also to different extra-physical applications. In this case, an urban planning process has been investigated, and by analyzing some decisive aspects, an ambiguous and absurd consequence such as the negation of second law validity, has been avoided.
\end{abstract}

Keywords: Heat exchangers, Quality index in thermal exchange, Chemical combustions, Environmental quality index, Information theory.

\section{INTRODUCTION}

By following a conceptual process entirely free from mechanical models and from posthumous settings, in 1909 the physicist-mathematician Carathéodory defined the entropy function as a simple Pfaffian differential, evaluated in function of the multiplication factor $\mathrm{T}^{-1}$ and according to two theorems of sufficiency and need $[1,2]$. Furthermore, he was able to validate the inevitable law of entropy growth for real processes, by formulating the mythical disequation $\mathrm{dS}^{(\mathrm{i})}>0$, where the superscript $i$ indicates the intrinsic genesis of the entropic increment due to irreversibility. In the same period, Gibbs and Nernst were able to carry out numerical calculations of entropy variation for different physical and chemical systems [3, 4]. However, beyond this pragmatic consolidation, the concept of entropy developed its polyhedric content, by evolving into more abstract and extra-physical thought areas [5], reaching philosophical connotations [6,7].

In this paper, by means of examples of tangible applications, the generalized role that entropy occupies in the study of some physical, chemical and extra-physical systems, has been investigated. In order to carry out an entropic analysis, the physical and chemical processes taken into account concern two practical cases of great interest in thermodynamic science: the transfer of thermal energy in heat exchangers and some combustion reactions. The entropy production in heat exchangers is theoretically quantified for the counterflow and parallel types and, subsequently, by means of a numerical approach, for a shell and tube device. In the physical and chemical considered systems, the calculated entropy production serves to determine preliminarily the optimum efficiency of the investigated heat exchanger and, subsequently, to evaluate the ecological goodness of some fuels in the production of heat.

With the creation of the theory of information (ShannonWeaver), the entropy concept extends its connotations, offering itself also for extra-physical applications $[8,9]$. In this field, in order to avoid negation of the validity of the second law of thermodynamics, different examples have been analysed by introducing the concepts of observer and user subsystems [10]. Therefore, the entropic study of the extraphysical processes requires the preliminary investigation on two basic notions: system and information, the latter involved by the order and disorder concepts [11]. In particular, an urban planning process, employed as the reference extraphysical system, has been exhaustively and thoroughly studied. Through the aforementioned information theory, other cases of extra-physical systems have been investigated, such as artistic creation and urban traffic.

\subsection{System definition}

In thermodynamic discussions, a more important aspect concerns the correct definition and identification of the 
reference system. The system is constituted by evolving elements (base system) and from a set of integrated subsystems (including the external environment). Among these subsystems, the observers assume a very important role since their presence is essential to verify the entropic balance of a generic process. For an entropic decrement in the base system, in fact, a major creation of entropy in the observer subsystem must be observed.

\subsection{Information: order and disorder concept}

With reference to the Prigogine opinion [12]: “...few notions are so embarrassing and difficult to assess in the limit of science as those of order and disorder ...", is evident that the concept of information has to be introduced, as well as the role of the observer as part of the evolving system. The information concept, according to the Shannon-Weaver definition (1948) [13,14], is determined by the relation:

$$
I=K \sum_{j=1}^{m} P_{j} \ln P_{j}
$$

where $P_{j}$ is the frequency of a $j_{t h}$ configuration, assuming that it is known in a set of $m$ possible configurations. Excluding the constant of normalization $K$, the formulation is identical to that of entropy introduced by Gibbs [15]. Therefore, despite the absolute independence of the two concepts, the entropy results in an index of information of a system. The more a system is disordered (elevated entropy production), the higher is the information that it provides. This concept appears as a contradictory statement, but it becomes true if a distinction between objective information and statistical and subjective information is carried out. The latter is the information that an observer receives from a more or less ordered state: the lower the entropy of the system, the greater the information received by the observer. By contrast, from statistical and objective points of view, the state of disorder (elevated entropy) makes the frequency (or the probability) to identify in the system a homogeneous configuration major. In the paper, the authors demonstrate how the study of physical, extra-physical and chemical systems in evolution can be conducted in a generalized manner. Therefore, entropy production can be quantified in terms of a Pfaff differential (Carateodory, heat exchangers case), by means thermodynamic calculations (Gibbs and Nerst, chemical combustions investigation) and, finally, by a preliminary study of the two basic concepts of system and information (advanced planning of an urban development plan). For this reason, the entropy can interpret physical, extra-physical and chemical processes by using simple algorithms, thermodynamic parameters and, finally, considering it as a transcendent entity.

\section{ENTROPY IN PHYSICAL PROCESSES}

The considered physical process, in order to develop an entropic analysis, concerns a practical case of great interest in thermodynamic science: the transfer of thermal power in counterflow, parallel and shell and tube heat exchangers. For the counterflow and parallel heat exchangers, the entropy production is theoretically evaluated through the Pfaff differential. For the shell and tube type, instead, the calculation was conducted numerically with a computer code developed by the authors by applying the classical thermodynamic theory and the laws of thermal balance. The key parameter is represented by the ratio between the entropy production and the delivered thermal power $(\Delta \dot{S} / \dot{Q})$, which allows a comparison among different types of heat exchanger by means of the following dimensionless parameter, representing the quality of the thermal exchange, which depends on the entropy degradation by the relation:

$$
i_{k s}=\left(1-\frac{\Delta \dot{S}}{\dot{Q}} \times \Delta T_{r e f}\right)_{k} \quad(k=1 \rightarrow n)
$$

Where $k$ identifies the type of heat exchanger, $n$ is the number of investigated heat exchangers, $\Delta \dot{S}$ is the entropic flux produced in the device, $\dot{Q}$ is the thermal power delivered between the fluids and $\Delta \mathrm{T}_{\text {ref }}$ is a reference temperature difference, evaluated as:

$$
\Delta T_{r e f}=T_{1 o}-T_{2 i}
$$

By considering a heat exchanger which operates with two fluids in indirect contact (Fig. 1), index 1 refers to the hot fluid flow rate while index 2 is related to the cold fluid flow rate. From Eq. (2), the entropic degradation index is unitary for null entropic productions; this condition occurs when the outlet hot fluid temperature reaches the inlet cold fluid temperature in a counterflow heat exchanger, and consequently the temperature difference of Eq. (3) is zero. Contrarily, in a parallel heat exchanger the quality index is always lower than 1 since the outlet hot fluid temperature at limit can reach the outlet cold fluid temperature, therefore also the reference temperature difference is greater than zero.

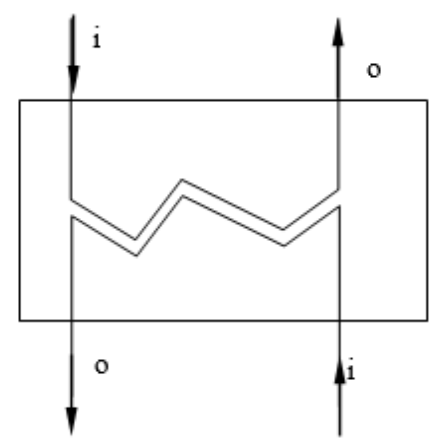

Figure 1. Sketch plan of the analysed heat exchanger: $i=$ inlet point, $\mathrm{o}=$ outlet point

\subsection{The entropy production in counter and parallel heat exchangers}

The inlet point of the heat exchanger was set correspondent to the inlet point of the hot flow rate; starting from this point, the generic exchange surface $\mathrm{A}_{\mathrm{X}}$ was evaluated, while $\mathrm{A}$ represents the effective heat exchange surface. 



Figure 2. Temperature distribution in parallel and counterflow heat exchangers

For a heat exchanger operating in steady-state conditions, the thermal power delivered is:

$$
\dot{Q}=c_{1} \cdot G_{1} \cdot\left(T_{1 i}-T_{1 o}\right)=c_{2} \cdot G_{2} \cdot\left(T_{2 o}-T_{2 i}\right)
$$

where $c$ is the fluid specific heat and $G$ the mass flow rate. Assuming an isobaric exchange process, the entropy production for unity of time is evaluated by $[16,17]$ :

$$
\Delta \dot{S}=c_{1} \cdot G_{1} \cdot \ln \frac{T_{1 o}}{T_{1 i}}+c_{2} \cdot G_{2} \cdot \ln \frac{T_{2 o}}{T_{2 i}}
$$

The production of entropy can be determined as the sum of two contributions, the first related to the decrement of entropy for the hot fluid flow rate and the other due to the growth of entropy of the cold fluid flow rate; the second contribution must prevail to guarantee irreversibility of the process. The ratio $\Delta \dot{S} / \dot{Q}$ connected to process irreversibility can be calculated by the relation [18]:

$$
\frac{\Delta \dot{S}}{\dot{Q}}=\frac{1}{T_{1 i}} \cdot\left\{\frac{\ln \left[\omega \cdot \tau^{*} \cdot(1-\tau)+1\right]^{\frac{1}{\omega}}}{1-\tau} \cdot \tau\right\}
$$

where:

$$
\omega=\frac{c_{1} G_{1}}{c_{2} G_{2}}
$$

and

$\tau^{*}=\frac{T_{1 i}}{T_{2 i}} \quad \tau=\frac{T_{1 o}}{T_{2 o}}$ for counterflow heat exchangers

$$
\tau^{*}=\frac{T_{1 i}}{T_{2 o}} \quad \tau=\frac{T_{2 i}}{T_{1 o}} \text { for parallel heat exchangers }
$$

A qualitative trend of the ratio $\Delta \dot{S} / \dot{Q}$ in function of heat exchange surface for counterflow and parallel heat exchangers is shown in Fig. 3 [18].

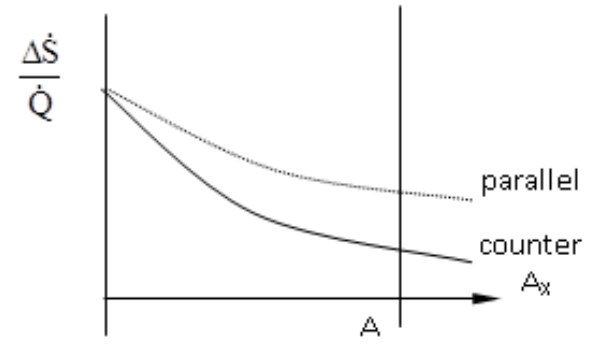

Figure 3. Specific entropy production per unit of delivered thermal power for parallel and counter heat exchangers

\subsection{The entropy production in shell and tube heat exchangers}

"Shell-and-tube" type heat exchangers are widely used in the field of thermal engineering and, more specifically, in power plants and air conditioning plants $[16,19]$. Therefore, their optimal operation condition, correspondent to a minimal entropy production in the process of heat exchange, leads both to a reduction of manufacturing costs and greater thermal efficiency. Different geometrical configurations of shell and tube heat exchangers are available for physical processes, therefore, a numerical approach is indicated to evaluate the entropic production in the thermal transfer process. The different types of shell and tube exchangers are also classified according to the position of inlet and outlet points of the fluids. The discretization of the physical model leads to the definition of elementary thermal units, generally called "cells" [20]. The mathematical model of every cell is represented by its heat balance equation, obtaining a system of equations that allows the determination of the efficiency and of the entropy production for any type of heat exchanger. Therefore, different configurations can be investigated in order to find the better geometrical solution to minimize the entropic production. In order to calculate the specific entropic production, the authors implemented an appropriate calculation program, validated by means of the theoretical results obtained for parallel and counter heat exchangers. A detailed description of the procedure and of the obtained results can be found in reference [21]. Fig. 4 shows the reference geometry of a shell-and-tube heat exchanger discretized by elementary cells to investigate thermal exchange [22, 23].

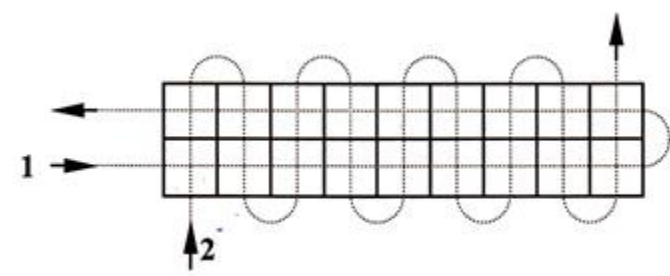

Figure 4. Physical scheme of a typical shell and tube heat exchanger

The physical discretization of the domain mathematically identifies a bi-dimensional matrix where the number of rows is equal to the number of cells $(M)$ and the number of columns represents the number of passages between two adjacent baffles in the heat exchanger $(N)$. Every pair of matrix indexes 
$i$ and $j$, identifies the cell, by providing the following equations:

$$
\begin{aligned}
& \dot{Q}=U \cdot \Delta A \cdot \Delta T_{a} \\
& \dot{Q}=c_{1} \cdot\left(T_{1 o}-T_{1 i}\right) \\
& \dot{Q}=-c_{2} \cdot\left(T_{2 o}-T_{2 i}\right)
\end{aligned}
$$

where $U$ represents the overall heat transfer coefficient of the heat exchanger.

Assuming that in every cell and for both fluids a complete heat exchange occurs, the following temperature difference can be set:

$$
\Delta T_{a}=T_{2 o}-T_{1 o}
$$

By indicating with $R$ the ratio between the thermal capacity and with $N T U$ the number of transfer units, the available parameters are sufficient to calculate the entropy production for every type of heat exchanger, in function of the number of passages $N$, the number of cells $M$ and, finally, the type of heat exchanger geometry $[24,25,26]$. The investigated geometry of shell and tube heat exchangers is shown in Fig. 5, in function of the position of the inlet and outlet points and of the number of passages (odd or even). Due to the temperature gradient between the involved fluids, the heat exchangers are affected by an important entropic production, therefore the more appropriate approach to study the process is represented by its entropic analysis [27]. For every cell, the delivered thermal power is equal to:

$$
\Delta \dot{Q}_{j}=c_{1} \cdot\left(T_{1 o j}-T_{1 i j}\right)=-c_{2} \cdot\left(T_{2 o j}-T_{2 i j}\right)
$$

Therefore, for the whole heat exchanger, results:

$$
\dot{Q}_{t o t}=\sum_{j} \Delta \dot{Q}_{j}
$$

The relation gives the entropy production for the two fluids and for time unit:

$$
\Delta \dot{S}_{1}=\frac{\Delta \dot{Q}_{j}}{T_{m 1 j}} \quad \text { and } \quad \Delta \dot{S}_{2}=\frac{\Delta \dot{Q}_{j}}{T_{m 2 j}}
$$

by setting:

$$
T_{m 1 j}=\frac{T_{1 i j}+T_{1 o j}}{2} \quad \text { and } \quad T_{m 1 j}=\frac{T_{2 i j}+T_{2 o j}}{2}
$$

So, the global entropy production can be evaluated by the sum:

$$
\Delta \dot{S}_{T O T}=\left(\Delta \dot{S}_{1 j}+\Delta \dot{S}_{2 j}\right)
$$

which can be employed to find the requested ratio $\Delta \dot{S} / \dot{Q}$ in order to quantify the irreversibility of the thermal exchange and, overall, to compare the different configurations of heat exchangers $[28,29]$.

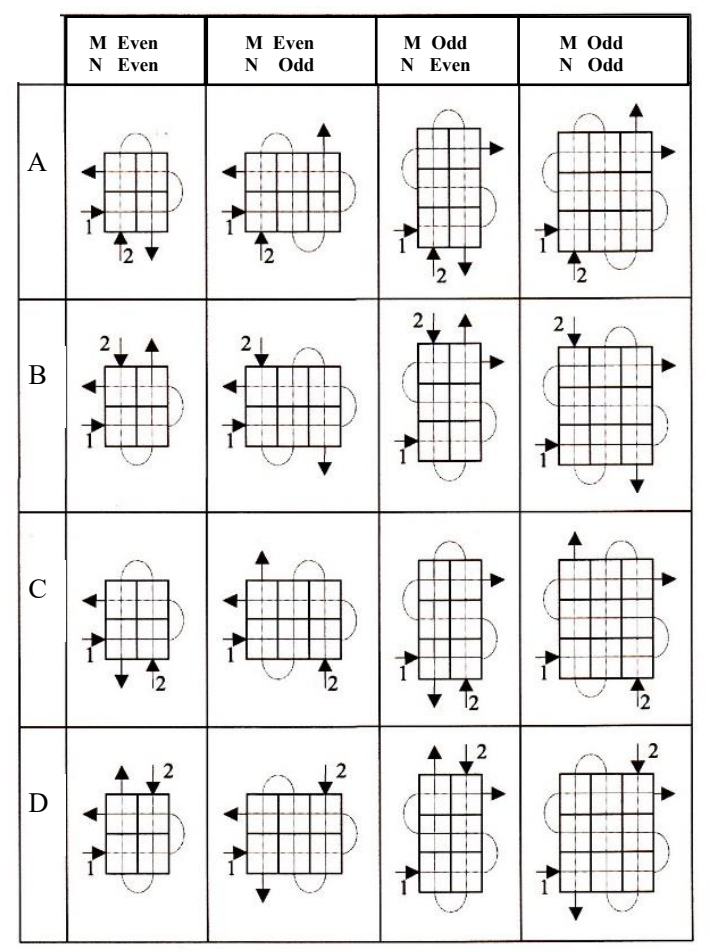

Figure 5. Investigated geometrical configuration of a shell and tube heat exchanger in function of the inlet and outlet points and of the number of passages of the cold flow rate

\subsection{Analytical evaluations}

In order to formulate a qualitative observation on the mechanism of thermal transfer in heat exchangers, Eq. (2) was applied to calculate the quality index of the heat exchange related to three different devices by setting the same thermal parameters. A counterflow type, a parallel one and the shell and tube heat exchanger shown in Fig. 4 with a unique passage in the shell and more passages in the tube, have been compared. The inlet temperature flow rate (diathermic oil, $\mathrm{c}_{1}=2500 \mathrm{~J} \cdot \mathrm{kg}^{-1} \cdot \mathrm{K}^{-1}$ ) was set to $180{ }^{\circ} \mathrm{C}$, while the cold flow rate is represented by water which enters at $20^{\circ} \mathrm{C}$. The hot fluid has the minimal value of the thermal capacity and the ratio is equal to 0.497 , while the overall heat transfer coefficient was set to $425 \mathrm{~W} \cdot \mathrm{m}^{-2} \mathrm{~K}^{-1}$. The obtained results, in function of the exchange surface, are shown in Fig. 6. The quality index increases with the exchange area for every investigated device; the shell and tube heat exchanger assumes a better position in the ranking compared to parallel ones, with a gap that increases with the increase of the exchange surface. For every area value, the counterflow heat exchanger presents the best quality indexes, and the higher the exchange area, greater are the deviations with the other investigated devices. The classical efficiency theory for heat exchangers provides unitary values of the thermal efficiency when the exchange surface of a counterflow device tends to infinity [26]. The employment of Eq. (2) implies the obtainment of the same result and, for every heat exchanger, the quality indexes are 
greater than the thermal efficiency values, but they assume the same meaning.

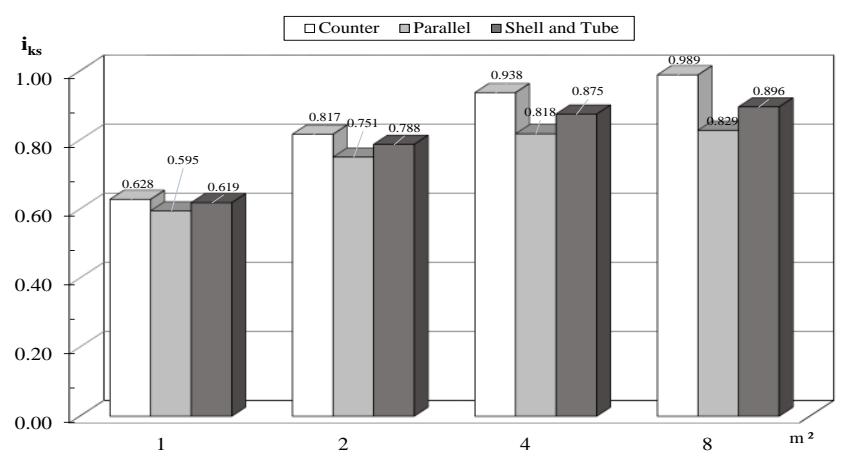

Figure 6. Quality indexes of the heat exchange for three different devices in function of the exchange surface

\section{ENTROPY IN CHEMICAL PROCESSES}

The thermodynamic analysis was conducted by means of the Gibbs theory, by evaluating the entropy production of some fuels during their combustion, in order to determine a correspondent environmental impact index. When a fuel is subjected to a free combustion process in an open system, an entropic production $\Delta \tilde{s}^{*}$ (in $\mathrm{J} \cdot \mathrm{mole}^{-1} \cdot \mathrm{K}^{-1}$ ) is observed. The combustion reactions represent an open thermodynamic system where the entropic variation is evaluated as the sum of two terms: the first intrinsic (always positive) linked to the process irreversibility and the other extrinsic (positive or negative) due to the heat exchange through the border of the thermodynamic system [30]. Moreover, the combustion processes involve not only a chemical expansion work $\Delta(\mathrm{p} \cdot \mathrm{v})$, but also a generalized chemical work $\Delta \mathrm{L}_{\text {chem }}=(\Delta \mu \cdot \mathrm{N})$, therefore the first and second thermodynamic laws in differential terms can be written in the form:

$$
T \cdot d s \geq d u+p \cdot d v-\Delta L_{c h e m}
$$

The produced chemical work plays a decisive role, in order to quantify both the above entropy change, but also the enthalpy of formation and the Gibbs potential of the chemical reaction [31]. The variation of the Gibbs potential, per mass unit, related to chemical combustion is calculated as:

$$
\Delta g=\Delta u+\Delta(p v)-\Delta(T s)-\Delta(\mu n)
$$

The latter variation transfers the energy content of the initial component in an available energy rate $\Delta \mathrm{h}$, and in a nonavailable energy rate evaluated by:

$$
\Delta(T s+\mu n)=\Delta\left(T s^{*}\right)
$$

where $\mathrm{s}^{*}$ is a fictitious parameter that includes both the total entropy for mass unit and the intrinsic chemical work of the reaction [32]. By modifying Eq. (18), the Gibbs potential can also be rewritten as:

$$
\Delta g=v \cdot \Delta P-s^{*} \cdot \Delta T
$$

If the chemical combustions of hydrogen (a), coal (b), methane (c) and gasoline (d), in function of their stoichiometric coefficient, are considered:

$$
\begin{array}{ll}
\circ & 1 \cdot \mathrm{H}_{2} \mathrm{O}-1 \cdot \mathrm{O}_{2}-0.5 \cdot \mathrm{O}_{2}=0 \\
\circ & 1 \cdot \mathrm{CO}_{2}-1 \cdot \mathrm{C}-1 \cdot \mathrm{O}_{2}=0 \\
\circ & 1 \cdot \mathrm{CO}_{2}+2 \cdot \mathrm{H}_{2} \mathrm{O}-1 \cdot \mathrm{CH}_{4}-2 \cdot \mathrm{O}_{2}=0 \\
\circ & 8 \cdot \mathrm{CO}_{2}+9 \cdot \mathrm{H}_{2} \mathrm{O}-1 \cdot \mathrm{C}_{8} \mathrm{H}_{18}-12.5 \cdot \mathrm{O}_{2}=0
\end{array}
$$

by using the molar values of $\Delta \tilde{h}, \Delta \tilde{s}^{*}, \Delta \tilde{g}$ reported in $[33$, $34,35,36,37,38]$ with the reference values of $\mathrm{P}_{0}=1 \mathrm{~atm}, \mathrm{~T}_{0}=$ $298 \mathrm{~K}, \mathrm{~s}_{0}=\mathrm{s}(\mathrm{p} \rightarrow 1 \mathrm{~atm})$, the investigated fuels can be compared by introducing an entropic degradation index defined by the relation $[39,40]$ :

$$
i_{j s}=\left(1-\left|\frac{\Delta \tilde{s}^{*} \cdot\langle T\rangle}{\Delta \tilde{h}}\right|\right)_{j} \quad(j=a \rightarrow d)
$$

where the subscript $j$ is related to the type of fuel, $\Delta \tilde{s}^{*}$ is the global entropy production during the combustion process $\left(\mathrm{J} \cdot \mathrm{mole}^{-1} \mathrm{~K}^{-1}\right), \quad<\mathrm{T}>$ is the absolute reference temperature, evaluated as average value between the reference and the combustion temperatures, finally, $\Delta \tilde{h}$ is the molar value of the enthalpy of reaction (in $\mathrm{J} \cdot \mathrm{mole}^{-1}$, assuming the same meaning of the fuel calorific power). The dimensionless index $i_{j s}$ ranging from 1 , in the ideal case where $\Delta \mathrm{s}^{*}=0$, to 0 in the worst case of total energy degradation. The latter case can be more accurately investigated by the analysis of the Gibbs potential variation [41]. By imposing $i_{j s}=1$ in Eq. (21), from Eq. (20) the following equality is obtained:

$$
\Delta \tilde{g}_{j}=\Delta \tilde{h}_{j}=v \cdot \Delta P-\tilde{s}^{*} \cdot \Delta T
$$

while the setting $i_{j s}=0$ provides:

$$
\Delta \tilde{h}_{j}=T \cdot \Delta \tilde{s}_{j}^{*} \quad \text { or } \quad v \cdot \Delta P=\tilde{s}^{*} \cdot \Delta T
$$

Table 1. Thermodynamic combustion parameters, reference temperature and quality indexes

\begin{tabular}{|c|c|c|c|c|c|}
\hline \multirow{2}{*}{ Fuels } & $\Delta \tilde{h}$ & $\Delta \tilde{s}^{*} \mathbf{s}^{-}$ & $\Delta \tilde{g} \boldsymbol{*}$ & $<\mathrm{T}>$ & $\mathrm{i}_{\mathrm{js}}$ \\
\cline { 2 - 6 } & $(\mathrm{J} / \mathrm{mole})$ & $(\mathrm{J} / \mathrm{mole} \cdot \mathrm{K})$ & $(\mathrm{J} / \mathrm{mole})$ & $(\mathrm{K})$ & $(-)$ \\
\hline $\mathrm{H}_{2}$ & -251.1 & 56.6 & -0.39 & 1451 & 0.672 \\
\hline $\mathrm{C}$ & -394.5 & 57.4 & -0.53 & 1285 & 0.813 \\
\hline $\mathrm{CH}_{4}$ & -870.5 & 90.9 & -1.05 & 1155 & 0.879 \\
\hline $\mathrm{C}_{8} \mathrm{H}_{18}$ & -5486.5 & 1644.5 & -11.69 & 2035 & 0.390 \\
\hline
\end{tabular}


The latter equation, in the case of maximum entropic degradation, shows that the temperature growth $\Delta \mathrm{T}$ produced by combustion leads to a global energy transformation in mechanical work, or rather in an expulsion work of the combustion products, with no advantages in terms of reaction heat. In function of the values of the aforementioned thermodynamic parameters and of the reference temperature, the dimensionless entropy indexes have been calculated by assuming standard combustions. The results are listed in Tab. 1 together with the investigated thermodynamic parameters and the reference combustion temperature.

A better evaluation of the obtained results can be conducted by means of a normalized index calculated in function of the maximum obtained value by the following relation:

$$
i_{j S}^{*}=\frac{i_{j s}}{\left(i_{j s}\right)_{M A X}} \cdot 100
$$

that allows an immediate comparison among the considered fuels. The results are shown in the graphs in Fig. 7. The rankings show a better position of hydrogen compared to gasoline, while coal and methane are placed, respectively, in first and second place. The calculations made for coal were obtained hypothesizing it in gaseous form as $\mathrm{CO}$, thus its position in the ranking lacks any meaning. These thermodynamic conclusions regarding the different combustions highlight a moderately positive judgment on hydrogen as a better vehicle fuel in the future in the transport sector to reduce, for instance, ecological damage.

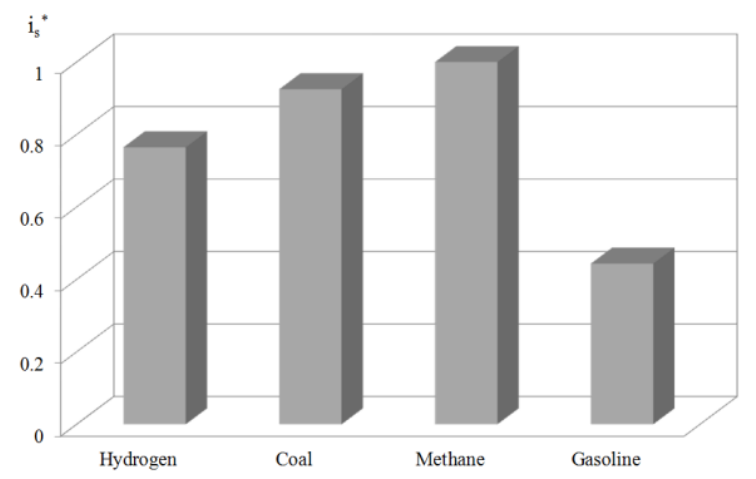

Figure 7. Entropy impact in the combustion analysis of hydrogen, coal, methane and gasoline

\section{ENTROPY IN EXTRA-PHYSICAL PROCESSES}

In this section, a rigorous calculation of the entropy production in some extra-physical processes has been carried out. In particular, a calculation concerning the entropy variation in urban planning operations has been addressed.

Other examples were investigated to demonstrate the validity of the thermodynamic second law also in this field.

\subsection{The entropy production in urban planning}

The progress in the planning of a well-defined urban area was considered as reference system by using the consolidated concept concerning the information theory [42]. The global entropy of the examined system can be determined by the relation:

$$
\mathrm{S}_{\mathrm{r}}=-k_{r} \cdot P_{r} \cdot \ln P_{r}
$$

where $r$ is a coefficient ranging from 1 to $m, k_{r}$ is a normalization constant and $P r$ is the frequency, or probability, that a precise configuration is identified in a field of possible $m$ different configurations. In the investigated case, the main system is represented by the chosen planning project, which evolves according to well-defined planning criteria. In this extra-physical system, other two sub-systems were identified: the passive observer (information user) and the planning designer (information source). When the project is still not started, the maximum value of entropy is observed, and the observer does not receive any information. With the progress of urban area planning, with more sophisticated designs and compositions, the order and the figurative structures increase, while entropy and objective information decrease. However, this decrement, in a dual manner, opposes the intrinsic entropy increase for the observer that, contextually, benefits from greater subjective information. The entropy-information balance, according to the thermodynamic second law, sets an active result due to the entropy increment of the whole system. From an analytical point of view, in accordance with the entropy concept introduced by Shannon and Weaver, the following functional has to either be minimized or made steady [43]:

$$
L=\sum_{r=1}^{m} \int_{x_{j o}}^{x_{j s}} S_{r} \cdot\left[\Phi_{r}\left(x_{j}\right)\right] \cdot d x_{j}
$$

The functions $\Phi_{\mathrm{r}}$ are called functional parameters: they depend on the coordinates and are chosen in $m$ units as characteristic components, or typical elements, of the investigated system. In the specific case, the functional parameters can be, for instance, the number of people per square meter, the private and public gardens, the surface of multi-floor existing buildings, the single-family buildings, the road and hydraulic network and the tertiary services. The following minimization of the functional and the correspondent $\mathrm{S}_{\min }$ calculation can be carried out by the traditional variational method reported in [43, 44]. From the knowledge of time $t$, the calculated entropy value allows to determine an appropriate index developed to evaluate the progress in the planning of the urban area:

$$
i_{s, t}=\left(1-\frac{\Delta t}{\Delta t_{0}}\right) \cdot\left(1-\frac{S}{S_{0}}\right)
$$

Therefore, the goodness of the planning progress is greater when the time $\Delta \mathrm{t}$ counted from the project beginning, evaluated with reference to an estimated maximum duration $\Delta t_{0}$, is lower. Furthermore, the quality of the project will be greater when the total entropy of the whole system is smaller, with reference to a conventional maximum value $S_{0}$. An analytical expansion of this procedure is reported in [45]. 


\subsection{Another example of entropy production: the urban traffic}

The reference system is represented by a part of a road network with length $\mathrm{L}$ delimited by two traffic lights: at $\mathrm{t}=0$, in front of the first red traffic light are placed $m$ cars in disordered way [46]. At the time $\mathrm{t}=0^{+}$, the traffic light becomes green and the cars begin to move in an ordered way by keeping this state until to the crossing of the second green traffic light. So, the disordered state at the first red traffic light has a maximum entropy value and it provides a greater objective information than the ordered state of the moving cars. Therefore, as a first impression, the system seems to evolve from an initial state of great entropy to a state characterized by a low entropy value, by negating the thermodynamic second law. Indeed, when the subsystem constituted by the set of active users (the car drivers) is inserted in the main system, at the entropy decrement related to the moving cars, a greater increment of the intrinsic entropy of the car drivers is opposed. Therefore, in contrast with the aforementioned objective information, an external observer receives a greater subjective information related to the ordered state of the moving cars than that related to the disordered state of the stopped cars.

\subsection{Another example of entropy production: artistic creations}

An unpainted canvas (evolving object), a painter (information source subsystem) and an observer (the information user) constitute the investigated system [47]. A monochrome canvas pigmentation is representative of an elevated entropic state with high objective information; instead, the user receives an objective null information. If the painter colours the canvas with an abstract and essential sketch, the order and the figurative structure increase, while entropy and subjective information of the system decrease. By thinking in terms of information, the balance of the whole system including the observer leads to an active result, preserving second law validity.

\section{CONCLUSIVE CONSIDERATIONS}

In this paper, the investigation of physical, extra-physical and chemical systems was conducted by an entropic analysis, by showing that the entropy concept is valid to quantify the efficiency and the goodness of different evolving processes. In the case of physical systems, counter, parallel and shell and tube heat exchangers were examined. The ratio $\Delta \dot{S} / \dot{Q}$ introduced in order to compare, with the same thermal parameters, different configurations of heat exchangers. Subsequently, an appropriate quality index concerning the thermal exchange was introduced in function of the entropic degradation of the physical process. In the case of elevated exchange surfaces, the quality index reaches a unitary value for counterflow heat exchangers whilst it tends asymptotically to a value lower than 1 for other types (as well as the thermal efficiency).

For the chemical process, entropy production in the combustion of hydrogen, coal, methane and gasoline was studied. By introducing a dimensionless index to quantify the thermodynamic quality, the obtained results have shown that hydrogen has a better position in the ranking than gasoline, while coal and methane are placed respectively at the first and second position. These results allow for moderate optimism regarding the future of hydrogen, both from an environmental and an entropic point of view. The results appear more significant if one considers that the coal evaluations were carried out by considering the data referring to its gaseous form $(\mathrm{CO})$ and that hydrogen can be sustainably produced by exploiting the solar source.

The analysis on extra-physical systems has highlighted that the validity of the thermodynamic second law is always respected if the observer subsystems are included in the evolving system. The entropic production has proved to be a suitable index to measure the environmental damage consequent to the planning of generic urban areas. The idea to involve the entropy concept under its form of information to study a generic extra-physical process is not new, and other examples can be found in [48, 49]. Thus, beyond the considered system of urban planning, urban traffic and artistic creations, other systems can be studied with reference to the concepts of order and information, such as, for instance, social systems and gem crystallization.

The obtained results demonstrate that entropy is suitable to be used to interpret any system, both as a simple algorithm and as a transcendent parameter. Therefore, entropy is a generalizable parameter, by demonstrating the validity of the concept reported by Prof. Arienti on the Entropie journal [11]: "De cette loi, Gomme d'un nid élevé, s'envola une sorte de phénix, l'entropie, qui commença une montée vers des mondes empirés. Depuis ce moment-là, jusqu'à ce jour, le vol n'a cessé et le cycle légendaire du phénix n'est pas encore accompli".

\section{REFERENCES}

1. Caratheodory C., Mathematische Annalen., $\mathrm{N}^{\circ} 67$, Berlin, 1909.

2. Sychev V.V., The Differential Equations of Thermodynamics, $2^{\text {nd }}$ edition, CRC Press, 1991.

3. Reiss H., Method of Thermodynamics, New York, 1965

4. Martyushev L.M., Seleznev V.D., "Maximum entropy production principle in physics, chemistry and biology," Physics Reports, $\mathrm{N}^{\circ}$ 426, pp. 1-45, 2006. DOI: 10.1016/j.physrep.2005.12.001.

5. Lestienne R., Les fils du temps: causalité, entropie, devenir, Presses du CNRS, Paris, 1990.

6. Somenzi V., Entropy, Information and Mind, BodyProblem, Information and Prediction, in Information and Prediction in Science, Academic Press, New York, pp. 229-235, 1965.

7. Ernst G., Huttemann A., Time, Chance, and Reduction: Philosophical Aspects of Statistical Mechanics, Cambridge University Press, 2010. DOI: 10.1017/CBO9780511770777.

8. Prigogine I., Introduction to Thermodynamics of Irreversible Processes, Wiley, New York, 1965. DOI: $\underline{10.1149 / 1.2425756}$

9. Prigogine I., Wiame J.M., «Biologie et thermodynamique des phénomènes irreversibles, » Experientia $\mathrm{N}^{\circ} 2$, pp. 451-453, 1946. 
10. I. Prigogine, La nascita del tempo. Le domande fondamentali della scienza dei nostri giorni, Ed. Theoria, Rome (Italy), 1991.

11. Arienti R., "Algorithme et transcendance, " Entropie $\mathrm{N}^{\circ}$ 166, Paris, 1991.

12. Gransdorff R., Prigogine I., Structure, Stabilité et Fluctuations, Ed. Masson, Paris (France), 1971.

13. Prigogine I., Les Lois du Chaos, Ed. Flammarion, Paris (France), 1994.

14. Longo G., Teoria dell'informazione, Ed. Boringhieri, Turin (Italy), 1980.

15. Gibbs J.W., Thermodynamics Vol. I, Dover Publications Inc., New York, 1906.

16. Sekulika D.P., "Entropy generation in a heat exchanger," in Heat Transfer Engineering, Taylor \& Francis, 1986. DOI: $10.1080 / 01457638608939647$.

17. Bejan A., "The concept of irreversibility in heat exchanger design: counter flow heat exchangers for gasto-gas applications," Journal of Heat Transfer, Vol. 99, 1977. DOI: $10.1115 / 1.3450705$.

18. Bielli U., De Giorgio G., Fattori G., Pedrocchi E., "Produzione di entropia negli scambiatori di calore," $L a$ Termotecnica $\mathrm{N}^{\circ}$ 11, Italy, 1978.

19. Ferrari P., Scambiatori di calore. Nuovo Colombo Manuale dell'ingegnere, Ed. Hoepli, Milan (Italy), p.156, 1985.

20. Kaul A.K., Mehta S.I., Sharma G.K., "Computer aided design and optimization of shell-and-tube heat exchangers," Journal of Thermal Engineering, vol. 2, n. 2,1981 .

21. Nicoletti G., Anile F., Marandola C., “L'entropia e l'efficienza negli scambiatori di calore degli impianti di condizionamento," in proceedings of the $57^{\circ}$ Italian Conference ATI, Pisa (Italy), 2002.

22. Gaddis E.S., Schlünder E.U., "Temperature distribution and heat exchange in multipass shell-and-tube exchangers with baffles," Heat Transfer Engineering, Vol. 1, N ${ }^{\circ} 1$, 1979. DOI: $10.1080 / 01457637908939548$.

23. Roetzel W., Spang B., "Effective mean temperature difference in segmentally baffled shell-and-tube exchangers," in proceedings of the 9th International Heat Transfer Conference, Jerusalem (Israel), 1990.

24. Nicoletti G., "Entropy Production in Shell and Tube Heat Exchangers," in proceedings of the 3rd European Thermal Sciences Conference, Heidelberg (Germany), 2000.

25. Afgan N., Schlünder E.U., Heat exchangers: Design and theory sourcebooks, McGraw Hill Book Company, New York, 1974.

26. Kays W. M., London A.L., Compact Heat Exchangers, McGraw Hill Book Company, New York, 1964. DOI: 10.1115/1.3644004.

27. Stoecker W.F., Design of Thermal Systems, McGraw Hill Book Company, New York, 1980.

28. Bejan A., Entropy Generation Minimization, CRC Pres, Boca Raton, U.S.A., 1996.

29. Nicoletti G., Anile F., "Studi parametrici di progettazione negli scambiatori di calore shell-and-tube," in proceedings of the $53^{\circ}$ Italian Conference ATI, Florence (Italy), 1998.
30. Nicoletti G., "Inquinamento atmosferico da combustione. Un approccio termodinamico," La Termotecnica (Italy), $\mathrm{N}^{\circ}$ 9, 1994.

31. Arienti R., Nicoletti G., "La definizione di un indice entropico ambientale di alcuni combustibili," in proceedings of the $45^{\circ}$ Italian conference ATI, Cagliari (Italy), 1990.

32. Arienti R., Nicoletti G., “Aspetti entropici dell'impatto ambientale da combustione," in Proceedings of the $4^{\circ}$ Yearly Italian Conference: Environmental Analysis in Italy, Milan (Italy), 1992.

33. Arienti R., Nicoletti G., et. al., Problemi risolti di Termodinamica, Ed. Patron, Bologna (Italy), 1988.

34. D'ans Lax, Taschenbuch für Chemiker und Physiker, Ed. Spinger Verlag, 1964.

35. Hutte B., Theoretische Grundlagen, $28^{\circ}$ Edition, Berlin (Germany), Springer Verlag, 1985.

36. Bornstein L., Chemische Handbuch, $6^{\circ}$ ed., vol. II/4 di W. Auer, 1950-1959.

37. Perry Chilton, Chemical Engineering Handbook, Mac Graw Hill, New York, 1973.

38. Weast, Handbook of Chemistry \& Physics, CRC Press, New York, 1961.

39. Nicoletti G., Caterisi S., Nicoletti Ge., "L'idrogeno come accumulatore di energia solare. Aspetti economici e termodinamici," in proceedings of the $67^{\circ}$ Italian Conference ATI, Trieste (Italy), 2012.

40. Nicoletti Gi., Arcuri N., Bruno R., Nicoletti Ge., "A technical and environmental comparison between hydrogen and some fossil fuels," Energy Conversion and Management, $\mathrm{N}^{\circ} 89$, pp. 205-513, 2015. DOI: 10.1016/j.enconman.2014.09.057.

41. Nicoletti G., Marandola C., "L'impatto ambientale nella produzione termo meccanica di energia elettrica," in proceedings of the $59^{\circ}$ Italian Conference ATI, Rome (Italy), 2005.

42. Arcidiacono G., Arcidiacono S., Entropia, sintropia, informazione. Una nuova teoria unitaria della fisica, chimica e biologia, 2nd Edition, Ed. Arcobaleno, Rome (Italy), 2006.

43. Troutman J.L., Variational Calculus with Elementary Convexity, Springer Verlag, Berlin (Germany), 1983. DOI: $10.1007 / 978-1-4684-0158-5$.

44. Courant \& Hilbert, Methoden der Mathematischen Physik, Berlin (Germany), 1931.

45. Arienti R., Nicoletti G., "Entropy: an extraphysical practical application. An entropic index for the state of development of a technical project," International Journal of Fluid Mechanics Research, 25 (4-6), New York, USA, 1998.

46. Cavallone S., Progettazione tecnica ed energia informazionale, Ed. PEG, Milan (Italy), 1991.

47. Arnheim R., Entropia e arte: saggio sul disordine e l'ordine, Ed. Einaudi Turin (Italy), 1982.

48. Dennery F.M., Précis de thermodynamique rationnelle: interprétations récentes des concepts et des principes, Masson, Paris (France), 1995.

49. O. Costa de Beauregard, Il $2^{\circ}$ principio della scienza del tempo, Entropia, informazione, irreversibilità, Ed. Franco Angeli, Milan (Italy), 1983. 